\title{
Analysis of the influence of Visceral Manual Therapy associated with Dry Needling on affections of the upper limbs.
}

\author{
Adson Ferreira Morais', Paulo Henrique Altran Veiga'
}

\begin{abstract}
Introduction: The viscera play a key role in the accommodation of recurring forces of their own weight, being influenced by the membranes that surround them. Analysis of the outermost membranes demonstrates that its anatomy makes direct connections with the membranes and fasciae that form the joint capsule of the shoulder. The functionality of this region is maintained through the synergism between these various membranes. One of the major causes of shoulder dysfunction is the lack of muscle flexibility and fascial adhesions that may interfere with the functionality of the shoulder joint. Objective: This study aims to compare the efficacy of visceral manipulation and dry needling and propose a therapeutic protocol for the capsular ligament affections of the shoulders. Method: Experimental study of pre and post cohort type, composed of 30 subjects with pain and decreased range of motion in the shoulder, performed from December 2016 to November 2017. Data collection was performed by electromyography, goniometry and visual analog scale (VAS) and immediately after was applied the visceral manipulation or dry needling or both and were reassessed. The data were submitted to a statistical analysis in which was used the software GraphPad Prism 4 with level of significance of $95 \%$ ( $p<0.05)$. Results: It was verified that there was a higher prevalence in the liver, it was also observed in post-application electromyography of the visceral mobilization and Dry Needling that the deltoid presented superior performance. Conclusion: The method mobilization and dry needling showed benefit for the glenohumeral joint, which may be others form of treatment.
\end{abstract}

Keywords: Visceral Manipulation; Dry Needling; Visceral Osteopathy.

\section{INTRODUCTION}

Visceral manipulation is a therapy developed by Dr. Jean-Pierre Barral, who described that the viscera have a key role in accommodating recurring loads of the membranes that surround it. In addition, it relies on the muscular action and forces applied externally, due to its disposition and flexibility. To this relationship work the viscera is surrounded by a membrane that extends into the extraperitoneal region. This membrane should be flexible to allow movement of the segments and nearby organs, otherwise its immobility may be the cause of joint dysfunctions. Thus, to perform most daily and recreational tasks is necessary a good visceral motility and mobility, restrictions and pain free $e^{(1-3)}$.

The decreased ability of visceral movements may produce adhesions or alter the normal biomechanics of the movement, predisposing the subject to injuries ${ }^{4}$. Similarly, there is a complex neuromuscular and fascial system involving static and dynamic elements, which are responsible for maintaining posture and shoulder movements. These require selective muscle actions and compatible with the demands of das activities of daily living (ADL) ${ }^{(5,6)}$. Visceral adhesions passively contribute to the joint stabilization and the movement impairment. The increased restraining forces in these cases lead to greater adhesions, provoking protective responses in the adjacent soft tissues attached to the peritoneum and could possible lead to tendonitis, bursitis or fasciitis secondary to these dysfunctions ${ }^{(7)}$.

The descriptions of Dr. Barral will be followed for the diagnosis of dysfunctions, analyzing the mobility (movement performed between the organs) and motility (inherent movement of the organ) of the myofascial tissues, observing where there are zones of greater tension. This process is called global auscultation. From a hypomobile zone, the tense zones denominated of local auscultation will be found with the specific palpation in the abdomen. Finally, through these zones, it is possible to identify that the causes of immobility will mainly be through fixations, ptosis and visceral spasms. Whereas the loss of mobility may be caused by ptosis, visceral spasms, articular restriction or generalized loss of the vitality of the organ which can be an early sign of the dysfunction ${ }^{(6,7)}$.

Any musculoskeletal alteration can lead to a visceral disturbance, due to the relationship that occurs through the viscerosomatic reflexes (the viscera loses its ability to slip, 
altering its functioning and creating a reflex that affects the physical structure) and somatovisceral (a physical structure can alter somehow the optimal functioning of the viscera $)^{(7)}$.

The shoulder is the joint most affected by painful syndromes, which affects ADLs and work and compromises the quality of life of many people. The painful shoulder can be caused by several etiologies, often associated, originating from the structures of the shoulder girdle or propagated from other regions ${ }^{(8)}$.

Dry needling is now one of the techniques used by the physiotherapist as part of the therapeutic arsenal of periarticular tissues, as well as acupuncture and neural therapy. Dry needling is possibly one of the techniques of physiotherapy that has experienced the greatest growth in Brazil and the rest of the world in recent years. This has been demonstrated in the large number of research studies and publications analyzing the efficacy of dry needling in the treatment of pain caused by Myofascial Trigger Points (MTrPs). These trigger points, admittedly, influence the contraction quality of the involved muscle, decreasing its capacity of optimal contraction and its maximum strength ${ }^{(9)}$. Dry needling treatment has also been applied in neurological patients for the treatment of shoulder pain with good results, although the technique of application is not different from those that are commonly used to treat pain of myofascial origin ${ }^{(10,11)}$.

Due to the findings in the literature, this study aims to analyze the possible effects of visceral mobilization and dry needling in the shoulder mobility and ligament capsular affections.

\section{METHOD}

This project is linked to the Physiotherapy course of the Center of Biological Sciences and Health of the Catholic University of Pernambuco, also linked to the research project "Analysis of the Influence of Visceral Manual Therapy in Upper Limb Disorders" coordinated by the Professor Paulo Henrique Altran Veiga, approved by the Ethics Committee (CAAE: 56390116.3.0000.5206), protocol number 1.871.884, as well as part of the research group "Physiotherapy Evidence Based". The work was carried out in Corpore Sano laboratories of the institution. The sample size was estimated in 30 people, following the inclusion criteria: decreased range of motion and pain in the shoulders of ligamentous capsule origin; subjects who agreed to sign the EHIC and presented a good cognitive level. Exclusion criteria included subjects with neurological motor alterations, sequelae of upper limb fractures, psychiatric alterations and histories of rheumatic diseases and patients with signs of needling phobia.

Firstly, the participants were evaluated through surface electromyography to analyze muscle activity in the resting phase and activity of the deltoid and supraspinatus muscles. A 4-channel electromyograph was used from the brand MIOTEC $^{\circledR}$. The electrodes were placed on the front part of the deltoid muscle at the level of the humeral head and the supraspinatus muscle and were also placed between the clavicle and the spine of the scapula on the upper part of the shoulder. The glenohumeral joints were evaluated through goniometry, to identify the range of motion. The goniometry was performed with a conventional goniometer, in which the axis was placed on the anterior face of the shoulder for evaluation of abduction and on the lateral face of the shoulder for evaluation of B submitted to the Visual Analogue Scale (VAS) questionnaire for pain assessment. All subjects underwent a global and local evaluation of the auscultation proposed by Jean Pierre Barral, in order to identify visceral dysfunctions.

In this evaluation the subjects were submitted to global palpation. This was performed with the patient in a standing position and the therapist, with a hand in the region of the head, asking the one to just relax. And the test is positive when the therapist feels the hand be taken in a certain direction, representing the organ that is in dysfunction. In the local auscultation the therapist rests his hand on the duodenum, jejunum, ileocecal, hepatopancreatic, cardiac and pyloric sphincters, located in the abdominal region of the patient. The test will be positive if the therapist's hand is "dragged" in a counterclockwise direction.

The dry needling was always performed by the same researcher, in points around the glenohumeral joint, between the wombs of the deltoid and supra-spinal muscles. Then the subjects, dressed in clothes suitable for the application of the technique manual visceral, were referred to a private room. All maneuvers were performed according to the results of the general and local auscultation, respecting the principles of Barral.

The sample was randomly randomized, with 10 patients in each group. A group was submitted to Dry needling (DRY); A group underwent visceral mobilization (VISC MOB); And a group was submitted to visceral mobilization and dry needling (VISC MOB+DRY). After performing the procedures all participants were reevaluated following the same parameters described previously. All data were sent to the statistician for analysis and inference.

\section{STATISTICAL ANALYSIS}

To describe the sample were used descriptive statistics techniques (mean, $\mathrm{n}$ and standard deviation). In order to test the assumptions of normality and homoscedasticity of the variables involved in the study was used the the Kolmogorov-Smirnov test. The identification of the means from the results of the Mobilization + Dry Needling (MOB+ DRY), Visceral Mobilization (MOB VISC) and Dry Needling (DRY) groups was performed through the paired Student's T-Test. When the data were not parametric was used the Man Witney test. The level of significance was $p \leq 0.05$. The data 
were entered in the Excel worksheet and the software used to obtain the statistical calculations was the GraphPad Prism $4{ }^{\circledR}$.

\section{RESULTS}

\section{Discussion}

Table 1 identifies the frequency of diagnosis for liver involvement, which is the most prevalent organ. In addition, it was observed that the dominant side had a variation between the right and left side, not showing prevalence between the two sides. We explain this prevalence of hepatic dysfunction in patients with right shoulder pain due to Glisson's capsule, in which there is sensory fibers for the right phrenic nerve; this explains that when there is a hepatic congestion with dysfunction in the liver (capsule distention), it is often found right diaphragmatic paralysis; and that the projection of liver pain is towards the right shoulder from the diaphragm and shoulder territory through a sensory innervation that comes from the same segment of the spine. Therefore, it is not the pain in the shoulder that should be treated, but the capsular distension caused by the dysfunction of the liver ${ }^{(14)}$.

Regarding the pain and discomfort of the left shoulder, some authors verify the viscero-somatic relationship with the facilitated segment provoked at the level of C7, attacking the tissues adjacent to the brachial plexus and consequently, the left shoulder. In addition, the gallbladder is the only hollow organ on the right, which has influence on the left shoulder. This is explained by its innervation through the left vagus nerve, which emanates from the gallbladder membrane and is related to the left diaphragmatic dome. In addition, there is a strong connection of the left pleural dome to the liver. This connection is strongly adhered to the thoracic fascia, which thickens significantly to constitute the cervico-thoracic diaphragm ${ }^{(15,16)}$. Within this, the ligaments that suspend the dome of the diaphragm prevent the reduction of the space through which the brachial plexus passes, and consequently, causing epicondylitis, bursitis, thoracic outlet syndrome, among others.

On the data in table 2, the authors of this study believe that these results are due to the compensation that the deltoid performs in the presence of weakening of the rotator cuff muscles, as is the case of the supraspinatus. This thought is in accordance with Pegreffi et al. ${ }^{(17-20)}$, who demonstrated the importance of shoulder stabilization by mediating the rotational center at the level of the glenoid joint surface, thus increasing the arm of the momentum of the deltoid muscle and consequently increasing its recruitment, compensating for weakness of the rotator cuff muscles ${ }^{(28,29)}$. Moreover, it is known that changes in the balance between the shoulder muscles lead to multidirectional instabilities, which can culminate with bursa and tendinous lesions and clinically present itself with the weakness of the cuff, forcing the deltoid to raise its electromyography response in order to improve the stabilization of the adjacent glenohumeral joint ${ }^{(28)}$.

In table 3, all subjects improved their pain, as well as, in figures $a, b$ and $c$ of the the graph 1 , it was verified that all groups showed increase in ROM after the procedures. It can be observed that the main characteristic of the Dry Needling is the deactivation of trigger points, leading the patient to have

Table 1. Characterization of the group, gender, age, dominant side and treated organ.

\begin{tabular}{lcccc}
\hline $\begin{array}{c}\text { GROUP } \\
\text { (n) }\end{array}$ & $\begin{array}{c}\text { GENDER } \\
\text { M/F }\end{array}$ & $\begin{array}{c}\text { AGE } \\
\text { (M/SD) }\end{array}$ & $\begin{array}{c}\text { DOMINANT } \\
\text { SIDE (R/L) }\end{array}$ & $\begin{array}{c}\text { LIVER/ KIDNEY/ } \\
\text { STOMACH/ OVARY/ } \\
\text { SPLEEN }\end{array}$ \\
\hline $\begin{array}{l}\text { MOB+DRY } \\
(10)\end{array}$ & $1 / 9$ & $37.10 / 18.05$ & $5 / 5$ & $6 / 2 / 1 / 1 / 0$ \\
$\begin{array}{l}\text { VISC MOB } \\
(10)\end{array}$ & $3 / 7$ & $26.10 / 12.27$ & $6 / 4$ & $6 / 3 / 0 / 0 / 1$ \\
DRY (10) & $3 / 7$ & $36.00 / 15.76$ & $5 / 5$ & $-\cdots$ \\
\hline
\end{tabular}

Note: $\mathrm{M}=$ mean; $\mathrm{SD}=$ standard deviation; $\mathrm{n}=$ absolute number; $\mathrm{M}=$ male; $\mathrm{F}=$ female; $\mathrm{L}=\mathrm{left}$; $\mathrm{R}=$ right.

Table 2. Comparison of the initial and final results of EMG, deltoid and supraspinatus muscles, before and after Dry Needling and visceral manipulation.

\begin{tabular}{lccc}
\hline \multicolumn{1}{c}{ GROUPS } & $\begin{array}{c}\text { EMG (Hz) } \\
\text { INITIAL } \\
\text { Mean } \pm \text { SD }\end{array}$ & $\begin{array}{c}\text { EMG (Hz) } \\
\text { FINAL } \\
\text { Mean } \pm \text { SD }\end{array}$ & $\begin{array}{c}\text { T test } \\
\text { p-value }\end{array}$ \\
\hline $\begin{array}{l}\text { MOB+DRY } \\
\text { (DELTOID) }\end{array}$ & $9.154 \pm 0.4796$ & $9.350 \pm 0.6479$ & $0.0499 *$ \\
$\begin{array}{l}\text { MOB+DRY } \\
\text { (SUPRA) }\end{array}$ & $9.223 \pm 0.6516$ & $8.959 \pm 0.6665$ & 0.0852 \\
$\begin{array}{l}\text { VISC MOB } \\
\text { (DELTOID) }\end{array}$ & $9.419 \pm 0.7967$ & $9.587 \pm 1.291$ & 0.2960 \\
$\begin{array}{l}\text { VISC MOB } \\
\text { (SUPRA) }\end{array}$ & $9.463 \pm 0.6110$ & $9.313 \pm 0.4445$ & 0.1198 \\
$\begin{array}{l}\text { DRY } \\
\text { (DELTOID) }\end{array}$ & $8.875 \pm 0.5430$ & $9.063 \pm 0.4253$ & 0.1617 \\
$\begin{array}{l}\text { DRY } \\
\text { (SUPRA) }\end{array}$ & $9.517 \pm 0.8668$ & $9.479 \pm 0.4509$ & 0.4292 \\
\hline
\end{tabular}

Note: $\mathrm{EMG}=$ electromyography; $\mathrm{Hz}=\mathrm{Hertz} ; \mathrm{SD}=$ standard deviation; $\mathrm{cm}=$ centimeters; Komogorov Smirnov test; $\mathrm{T}$ test for paired samples; Statistically significant difference for $p$-value $\leq 0.05 \%$.

Table 3. Comparison of the initial and final results of the Visual Analogue Scale, flexion, extension, abduction and adduction movements, before and after Dry Needling and visceral manipulation.

\begin{tabular}{lllll}
\hline \multicolumn{1}{c}{ GROUPS } & $\begin{array}{l}\text { Flexion } \\
\text { p-value }\end{array}$ & $\begin{array}{c}\text { Extension } \\
\text { p-value }\end{array}$ & $\begin{array}{c}\text { Abduction } \\
\text { p-value }\end{array}$ & $\begin{array}{c}\text { Adduction } \\
\text { p-value }\end{array}$ \\
\hline MOB+DRY & $0.0001^{* * * \psi}$ & $0.0064^{* *}$ & $0.0004^{* * *}$ & $0.0015^{* * \psi}$ \\
MOB & $0.0005^{* * *}$ & $0.0001^{* * *}$ & $0.0002^{* * *}$ & $0.0028^{* *}$ \\
DRY & $0.0003^{* * *}$ & $0.0005^{* * *}$ & $0.0009 * * *$ & $0.0001^{* * *}$ \\
\hline
\end{tabular}

Note: $\mathrm{MOB}=$ visceral manipulation; $\mathrm{DRY}=$ Dry Needling; $\mathrm{T}$ test for paired samples; Statistically significant difference for $p$-valor $\leq 0.05 \%$ *. Man Witney test for non-parametric samples $\Psi$. 
a)

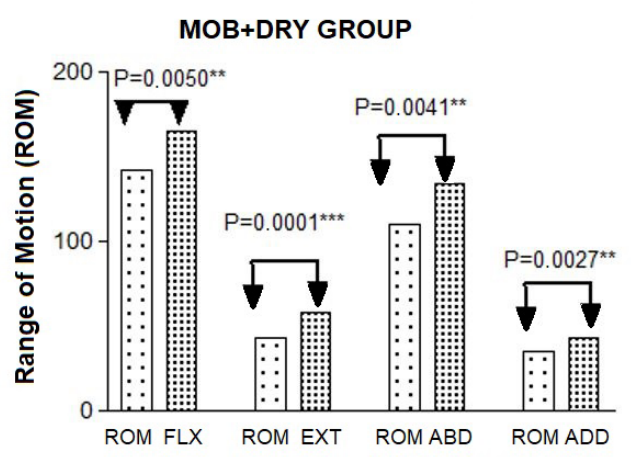

b)

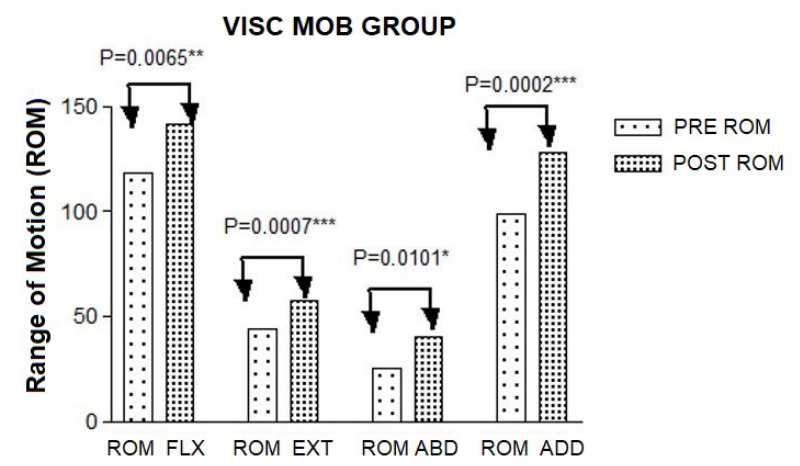

c)

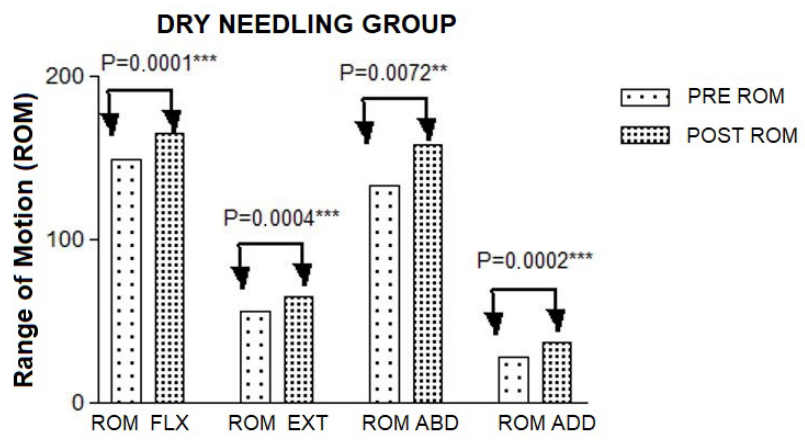

Graphic 1. Comparison of the initial and final results of the range of motion in flexion, extension, abduction and adduction movements, before and after Dry Needling and Visceral Manipulation.

Note: $\mathrm{MOB}=$ visceral manipulation; $\mathrm{DRY}=$ Dry Needling

a sense of well-being and a decrease in the pain due to the release of endorphin and other substances. The technique is quick and with a very low pain threshold, and soon after the application of the needle there is a decrease in pain and an increase in range of motion, normalization of muscle activation patterns and improvement in function ${ }^{(17-20)}$. The principal immediate effect after applying or within the first 24 hours is the minimum reduction of pain in the following days. The instantaneous improvement of ROM can be explained by the stretching of the muscle fibers, allowing the resumption of normal length of the fibers, thus increasing the excursion of the movement ${ }^{(12)}$. These factors probably led to an improvement in the motion of the study subjects ${ }^{(21-24)}$.

After the visceral mobilizations, the movement that occurs between the organs is stimulated through the peritoneal slip. The adhesions that are formed can be literally broken, promoting improvement of ROM of the joints that have chain relation with these organs. As previously mentioned, the relation of the peritoneal membrane on the movements of the shoulder and its influence on the liver and gallbladder may restrict or release the glenohumeral joint ${ }^{(25-28)}$. As seen in Grafic 1 subdivided a, b and c, Dry Needling and visceral mobilization improve the ROM and seem to have resulted in improved movement of these joints, corroborating with the authors mentioned.

\section{FINAL CONSIDERATIONS}

According to the EMG study, the result that obtained most significance was the visceral manipulation and Dry Needling for the deltoid muscle. Considering the analyzes of the present study, it was verified that there was an improvement of the range of motion and reduction in pain, improving the disability after the visceral manipulation, Dry Needling or both.

However, there was a limitation in this study regarding the size of the evaluated sample. It is recommended that further research be done with a larger sample size in order to better exploit the results. The authors also suggest the insertion of the control group for later comparisons, which is being provided through the authors' research group.

\section{AUTHORS' CONTRIBUTIONS}

PHAV and AMF elaborated the study design; PHAV and AMF performed the data collection; PHAV performed the statistical analysis; AMF and PHAV performed the critical intellectual review of the manuscript. All authors read and approved the final manuscript.

\section{CONFLICT OF INTEREST}

Nothing to declare.

\section{REFERENCES}

1. Minkalis $A L$, Vining RD, Long $C R$, Hawk CL, Luca $K T$. A systematic review of thrust manipulation for non-surgical shoulder conditions. Chiropr Man Therap. 2017;25(1):1-10. 
2. Almeida CCV, Barbosa CGD, Araújo AR, Braga NHM. Relação da fáscia tóraco lombar com o mecanismo ativo de estabilização lombar. R. bras. Ci. e Mov. 2006;14(3):105-112.

3. Voigt L, Vale RGS, Abdala DW, Freitas WZ, Novaes JS, Dantas EHM. Efeitos de uma repetição de dez segundos de estímulo do método estático para o desenvolvimento da fexibilidade de homens adultos jovens. Fit Perf J. 2007;6(6):352-356.

4. Kisner C, Colby LA. Exercícios terapêuticos: fundamentos e técnicas. 6a ed. São Paulo: Manole; 2005. In: Shuback, B; Hooper,J.; Salisbury,L. A comparision of a self-strech incorporating proprioceptive neuromuscular facilitation components and a therapist-applied PNF-technique on hamstring flexibility. Physiotherapy. 2004;90:151-157.

5. Yeng LT, Kaziyama HHS, Teixeira MJ. Síndrome dolorosa miofascial. JBA, Curitiba, v.3, n.9, p.27-43, jan./mar. 2003.

6. Bienfait M. Bases Physiologiques de La Therapie Manuelle et de L'osteopathie, 2000. A systematic review. Cephalalgia. 2014;34(12):9941003.

7. Barral JP, Mercier P. Visceral Manipulation. Seattle: Eastland Press Inc.; 2005.

8. Barral JP, Visceral Manipulation II. Seattle: Eastland Press Inc.; 2007.

9. Lech O, Severo A. Ombro e cotovelo. In: Hebert S, Xavier R. Ortopedia e traumatologia: princípios e prática. $2^{\text {a }}$ ed. Porto Alegre: Artmed; 1998. p. 124-154.

10. Fresno MJ, Mediavilla P, Mayoral O. Dry needling of miofascial trigger points for hypertonia spastica in incomplete spinal Cord injuries. Report of two cases. J Musculoskelet Pain. 2004;12(Suppl 9):75 [abstract].

11. Dilorenzo L, Traballesi M, Morelli D, Pompa A, Brunelli S, Buzzi MG, et al. Hemiparetic shoulder pain syndrome treated with deep dry needling during early rehabilitation: a prospective, open-label, randomized investigation. J Musculoskelet Pain. 2004;12:25-34.

12. Osborne NJ, Gatt IT. Management of shoulder injuries using dry needling in elite volleyball players. Acupuncture in Medicine. 2010;28(1):42-45.

13. Huang YT, Neoh CA, Lin SY, Shi HY. Comparisons of prediction models of myofascial pain control after dry needling: a prospective study. Evid-Based Compl Alt. 2013; Jun 18.

14. Huang YT, Lin SY, Neoh CA, Wang KY, Jean YH, Shi HY. Dry needling for myofascial pain: prognostic factors. J Altern Complement Med. 2011;17(8):755-762.

15. Barral J, Croibier A. Visceral vascular manipulations. Churchill Livingstone; 2011.

16. Paoletti S. The fascie: anatomy disfuncion \& tratament. Easteland Press; 2006.
17. Pegreffi F, Pellegrini A, Paladini A, Merolla G, Belli G, Velarde PU, et al. Deltoid muscle activity in patients with reverse shoulder prosthesis at 2-year follow-up. Musculoskelet Surg. 2017;101(Suppl 2):129-135.

18. Rock J, Rainey CE. Treatment of nonspecific thoracic spine pain with trigger point dry needle ligand intramuscular electrical stimulation: a case series. Int J Sports Phys Ther. 2014;9(5):699-711.

19. Koppenhaver SL, Walker MJ, Rettig C, Davis J, Nelson C, Su J, et al. The association between dry needling-induced twitch response and change in pain and muscle function in patients with low back pain: a quasiexperimental study. Physiotherapy. 2017;103(2):131-137.

20. Dar G, Hicks GE. The immediate effect of dry needling on multifidus muscles' function in healthy individuals. Journal of Back and Musculoskeletal Rehabilitation. 2016;29(3):273-278.

21. Finet, G. Treating Visceral Dysfunction: An Osteopathic Approach to Understanding and Treating the Abdominal Organs. Stillness Press, Portland, OR; 2000.

22. Souza KRSB. A ação do tratamento do agulhamento a seco no controle da síndrome dolorosa miofascial. Goiânia. Monografia [Pós-graduação em reabilitação em ortopedia e traumatologia com ênfase em terapia manual]- Faculdade Cambury; 2013.

23. Hueguenin L, Brukner PD, McCrory P, Smith P, Wajswelner H, Bennell $K$. Effect of dry needling of gluteal muscles on straight leg raise: a randomised, placebo controlled, double blind trial. British Journal of Sports Medicine. 2005;39(2):84-90.

24. Kietrys DM, Palombaro KM, Azzaretto E, Hubler R, Schaller B, Schlussel JM, et al. Effectiveness of Dry needling for upper-quarter myofascial pain: a systematic review and meta-analysis. Journal of Orthopedic and Sports Physical Therapy. 2013;43(9):620-634.

25. Ong J, Claydon LS. The effect of dry needling for myofascial trigger points in the neck and shoulders: a systematic review and meta-analysis. J Bodyw Mov Ther. 2014;18(3):390-398.

26. Myers, TW. Trilhos Anatômicos. Meridianos Miofasciais para terapeutas manuais e do movimento. 2a edição. Brasil: Elsevier; 2010.

27. Moreira D, Godoy JR, Silva Junior W. Anatomia e cinésiologia clínica do aparelho do movimento. 1a edição. Brasil: Thesaurus; 2004.

28. Walker BF, Hebert JJ, Stomski NJ, Clarke BR, Bowden RS, Losco B, et al. Outcomes of usual chiropractic. The $\mathrm{OUCH}$ randomized controlled trial of adverse events. Spine. Phila Pa 1976. 2013;38:1723-29.

29. Bove, GM, DC, Chapelle, SL, Visceral mobilization can lyse and prevent peritoneal adhesions in a rat model. J Bodyw Mov Ther. 2012;16:76-82. 